\title{
Sense of Coherence in Patients with Inflammatory Bowel Disease
}

\author{
Randi Opheim, ${ }^{1,2}$ May Solveig Fagermoen, ${ }^{1,3}$ Lars-Petter Jelsness-Jørgensen, ${ }^{4,5}$ \\ Tomm Bernklev, ${ }^{6}$ and Bjørn Moum ${ }^{1,2}$ \\ ${ }^{1}$ Department of Gastroenterology, Division of Medicine, Oslo University Hospital, P.O. Box 4956, Nydalen, 0424 Oslo, Norway \\ ${ }^{2}$ The Institute of Clinical Medicine, University of Oslo, P.O. Box 1171, Blindern, 0318 Oslo, Norway \\ ${ }^{3}$ Department of Nursing Science, Institute of Health and Society, University of Oslo, P.O. Box 1130, Blindern, 0318 Oslo, Norway \\ ${ }^{4}$ Østfold University College, K.G. Meldahlsvei 9, 1671 Fredrikstad, Norway \\ ${ }^{5}$ Department of Gastroenterology, Østfold Hospital Trust, 1603 Fredrikstad, Norway \\ ${ }^{6}$ Research and Development Department, Telemark Hospital Trust, 3710 Skien, Norway
}

Correspondence should be addressed to Randi Opheim; randi.opheim@medisin.uio.no

Received 5 November 2013; Accepted 29 November 2013; Published 2 January 2014

Academic Editor: Spiros D. Ladas

Copyright (C) 2014 Randi Opheim et al. This is an open access article distributed under the Creative Commons Attribution License, which permits unrestricted use, distribution, and reproduction in any medium, provided the original work is properly cited.

Background and Aim. Sense of coherence (SOC) is a health-promoting concept reflecting a person's view of life and response to stressful situations and may be of importance in coping with chronic illness. The aim of this study was to explore associations between SOC and sociodemographic, disease-related, and personal characteristics in a sample of patients with inflammatory bowel disease (IBD). Methods. Measures included sociodemographic and disease-related data, the Sense of Coherence Scale, General SelfEfficacy Scale (GSE), and Fatigue Severity Scale (FSS-5). Results. In total, 428 IBD patients had evaluable questionnaires (response rate 93\%). The overall mean SOC total score was 66.25 (SD 11.47) and with no statistically significant difference between patients with ulcerative colitis (UC) and patients with Crohn's disease (CD). In the multivariate analyses, higher GSE scores were significantly associated with higher SOC scores and higher FSS-5 scores were significantly associated with lower SOC scores in both UC and CD. Conclusion. GSE and FSS-5 contributed more to the variance in SOC than sociodemographic and disease-related variables. Longitudinal studies are warranted to investigate the value of SOC as a predictor of disability, medication adherence, coping behavior, and health-related quality of life.

\section{Introduction}

The inflammatory bowel diseases (IBD), Crohn's disease (CD), and ulcerative colitis (UC) are chronic inflammatory disorders of the gastrointestinal tract of unknown etiology. The course of disease is characterized by periods of symptom flares and periods with quiescent disease. Common symptoms are diarrhea, bloody stools, fever, fatigue, and abdominal pain [1-3]. As with many chronic diseases, IBD patients' quality of life and psychosocial function have been shown to be influenced by their disease [4-8]. Further, patients diagnosed with IBD at a young age and with a severe disease course have an increased risk for work disability [9].

Coping with a chronic illness such as IBD involves complex cognitive, physical, emotional, psychological, and behavioral processes [5]. Patients must be able to manage complex medication regimens, find meaning in and adapt to changeable life conditions, and deal with emotions associated with the fact that the disease is not curable. The unpredictable disease course also poses challenges for the patients' daily life as well their life in general [10]. Given the complexity of living with a chronic illness, personal resources may be of importance for patients' well-being, quality of life, and ability to cope with their disease.

The concept "sense of coherence" (SOC) is used to describe a person's capacity to respond to stressful situations, such as chronic illness. The concept was introduced by the medical sociologist Antonovsky in his theory of salutogenesis, which focuses on personal resources needed to move toward and maintain health [11]. SOC consists 
of a motivational component (meaningfulness), a cognitive component (comprehensibility), and a behavioral component (manageability) [11]. Confronted with a stressor, a person with a high SOC is motivated to cope (meaningfulness) and believes that the challenge is understood (comprehensibility) and that the resources to cope are available (manageability) [11]. Systematic reviews of research on SOC in general populations and in chronic diseases conclude that SOC is strongly related to a person's mental health [12], is associated with health behaviors [13], and has a substantial impact on health-related quality of life (HRQoL) [14]. In addition, SOC is applicable in learning processes and evaluation of education programs $[15,16]$ and is found to be a predictor for medication adherence [17].

Results from studies of people with other chronic diseases and in the general population indicate that sociodemographic variables, such as age, gender, relationship status, educational level, and work status, may influence SOC $[15,18]$. Also, the presence of IBD with its relapsing and remitting disease course may play a role in the person's SOC [19]. However, the relationship between sociodemographic and disease-related variables and SOC has not been adequately studied in IBD patients.

Several studies have identified fatigue as one of the leading concern for IBD patients [20,21]. A qualitative explorative study found that the IBD patients reduced social and work activities in an attempt to manage fatigue [22]. Individuals who feel they can create environments appropriate to their psychological and physical needs experience less fatigue and fatigue-related stress [23]. Thus, a person's SOC may affect the experience of fatigue interference.

Self-efficacy, defined as a person's beliefs about their capability to perform the behaviors needed to obtain a desired outcome [24], is also found to be important for coping and health behavior. Previous research has shown that persons with high levels of self-efficacy show less reaction to psychological stress and are less prone to depression and anxiety than persons with lower levels of self-efficacy, suggesting a close relation between self-efficacy and coping [25]. Thus, when exploring SOC in IBD patients, the role of self-efficacy is important to consider.

Knowledge and understanding of the salutogenic framework and the SOC concept can help health professionals to understand the IBD patient's health/disease behaviors and choices, to complement clinical data. Because few studies have been undertaken to assess SOC in an IBD population, the aim of the present study was to explore associations between sociodemographic, disease-related, and personal variables and SOC in CD patients and UC patients.

\section{Materials and Methods}

2.1. Study Design and Study Population. This descriptive cross-sectional study examined IBD patients who attended outpatient clinics at hospitals in eastern, western, and southern Norway from October 1, 2009, to May 31, 2011. Patients who were $\geq 18$ years with previously verified IBD (clinical, endoscopical, and histological) were included after giving their informed consent. The patients were asked to complete self-administered questionnaires during a regular visit at the hospital but were also given the option to complete the questionnaires at home and return them in a stamped addressed envelope.

\subsection{Measurements}

2.2.1. Sociodemographic Variables. Collected data included age, gender, educational level (12 years (secondary) education or less versus more than 12 years (college/university education)), marital status (married or cohabitant versus single, divorced, or partnered but living separately), work status (working, including being a student versus not working, including pensioner and work disabled), and smoking status (yes (defined as once or more daily) versus no).

2.2.2. Disease-Related Variables. Data concerning medical history and past surgical history for IBD were obtained from the patients' medical records. The Montreal classification was used to classify disease location and behavior in CD and disease extent in UC [26]. Disease activity was measured with the Harvey-Bradshaw activity index (HBAI) in CD patients [27] and with the simple clinical colitis activity index (SCCAI) in UC patients [28]. The patient selfreported disease-related information regarding presence of comorbidities (any of the following: cardiovascular disease, diabetes, arthritis, arthralgia, asthma, dermatological disease, or cancer) and a history of any adverse drug reactions to conventional medications for their IBD (any of the following: nausea, abdominal pain, diarrhea, headache, fever, weight gain, mood changes, joint pain, sleep disturbance, or skin itch).

2.2.3. The Sense of Coherence Scale. To measure SOC, a 13item short version of the 29-item Sense of Coherence Scale was used [11]. The SOC instrument has been translated into 33 languages and studied in 32 countries, thus regarded as applicable to all cultures [15]. The Norwegian version was subjected to forward and backward translation according to recommended procedures [29]. SOC-13 measures the degree to which an individual views the world as comprehensible (5 items), manageable (4 items), and meaningful (4 items) using a 7-point Likert scale. The total SOC score is the sum of the items, ranging from 13 to 91 , and the subdimensions ranges 5-35 (comprehensibility) and 4-28 (manageability and meaningfulness). Higher scores reflect a stronger SOC. The SOC-13 scale is reported to be a reliable and valid instrument, with a reported internal consistency (Cronbach's $\alpha$ ) of 0.70 to $0.92[15,30]$. Internal consistency in this study was demonstrated with a Cronbach's $\alpha$ of 0.86 in the UC group and 0.85 in the CD group, which corresponds well with another Norwegian study [31] and which is considered good [32].

2.2.4. The General Self-Efficacy Scale. GSE [33] measures the strength of an individual's belief in his/her ability to cope with difficult demands in life. It consists of 10 statements 
that respondents rate on a scale from 1 "completely disagree" to 4 "completely agree." A GSE scores are calculated by summing each individual score (range 10 to 40 ). The GSE has been translated into several languages, including Norwegian [34]. The scale has been reported as a reliable and valid instrument [35]. Internal consistency in our study was 0.90 in both the UC and the CD groups, which corresponded well with another Norwegian study [36] and which is considered excellent [32].

2.2.5. The Five-Item Fatigue Severity Scale. FSS-5 was used to assess the experience of fatigue interference with activities of daily living [37]. Each item is scored on a 7-point Likerttype scale ranging from 1 (disagree) to 7 (fully agree). The mean of the five-item scores represents a continuous variable with values from 1.0 (no fatigue interference) to 7.0 (maximum fatigue interference). A higher score indicates higher fatigue interference. The original nine-item version has been validated in the Norwegian general population and in populations with chronic disease and has shown good psychometric properties [38, 39]. However, the five-item version was used in our study because it has been found to improve the psychometric properties of the FSS $[37,40]$. In our sample Cronbach's $\alpha$ was of 0.90 in the UC group and 0.88 in the $\mathrm{CD}$ group, indicating good internal consistency [32].

2.3. Statistical Analysis. Differences between groups were assessed with Chi-square $\left(\chi^{2}\right)$ test for categorical data and independent sample $t$-test for continuous variables with normal distribution. When the continuous variables had skewed distributions, they were described with medians and ranges, and differences between groups were tested using the nonparametric Mann-Whitney $U$ test. Pearson's correlation coefficient $(r)$ was used for bivariate correlation analysis. Multiple linear regression analyses were used to determine the associations between relevant sociodemographic and disease-related variables, and GSE and FSS-5 (independent variables) with SOC and its subdimensions (dependent variables). In addition to gender and age, variables with $P$ value $<0.10$ in bivariate analyses were entered into a multiple linear regression model. Sociodemographic variables were included in step 1, disease-related variables in step 2, fatigue interference in step 3, and self-efficacy in step 4 . The strength of association was determined by the standardized beta coefficient. None of the independent variables included in the final analyses were highly correlated (Pearson's correlation coefficient $>0.7$ ) with any other possible variable; thus we assumed no multicollinearity. Cronbach's $\alpha$ [41] was used to assess internal consistency of the scales. Because of multiple testing the level of significance was set to $1 \%$ in all analyses. All tests were two sided. Analyses were performed using SPSS for Windows [42].

2.4. Ethical Considerations. The Regional Committees for Medical and Health Research Ethics in Norway (reference number: S-00858b) and the internal data protection officer at Oslo University Hospital approved this study. All patients received verbal and written information about the study prior to providing written informed consent.

\section{Results}

Of the 460 patients included in the study after giving informed consent, 30 patients did not return the questionnaire after one reminder. Two patients did not complete the FSS-5, SOC-13, and GSE and were consequently excluded, leaving a representative sample of 428 patients (response rate $=93 \%$ ). The respondents and nonrespondents were comparable with regard to gender, age, disease duration, and type of diagnosis (data not shown).

Characteristics of the study sample are presented in Table 1. Compared to UC patients $(n=190)$, the CD patients ( $n=238$ ) were younger (38 versus 41 years, $P=0.019$ ) and a higher proportion was female (CD 55\% versus UC 43\%, $P=0.018)$. In addition, $C D$ patients had significantly longer disease duration (11 years versus 6 years, $P<0.001$ ) and a significantly higher proportion had undergone surgery for their IBD compared to the UC group (CD 55\% versus UC $7 \%, P<0.001)$. Among the UC patients, 55\% were classified with extensive disease, whereas $31 \%$ of the CD patients had penetrating disease behavior (complications such as fistulas and abscesses) (data not shown).

3.1. Distribution of SOC, FSS-5, and GSE. In the sample, SOC total scores ranged from 28 to 91 points, with a mean of 66.25 points $(\mathrm{SD}=11.47)$ and with no gender differences: $66.99(\mathrm{SD}=11.45)$ for men and $65.49(\mathrm{SD}=11.46)$ for women. Table 2 presents SOC, FSS-5, and GSE scores in the UC group and the $\mathrm{CD}$ group. No significant differences were found between UC and CD with regard to SOC total scores, the SOC subdimensions, or GSE scores (data not shown). The mean FSS-5 score was higher in CD patients $4.49(\mathrm{SD}=1.48)$ compared to UC patients $4.13(\mathrm{SD}=1.54), P=0.015$.

In the UC group, men had significantly higher GSE scores compared to women $(P=0.003)$. In the $\mathrm{CD}$ group, compared to women, men had significantly higher score on the SOC sub-dimension manageability $(P=0.007)$.

3.2. Bivariate and Multivariate Relationships to SOC. Bivariate relationships to SOC and its subdimensions are shown in Table 3. In both disease groups, higher GSE score was associated with higher SOC total and sub-dimension scores, and higher FSS-5 score was associated with lower SOC total and sub-dimension scores. In the UC group, disease activity was negatively associated with comprehensibility whereas, in the CD group, disease activity was negatively associated with manageability.

The linear regression analyses in $\mathrm{UC}$ and $\mathrm{CD}$ are shown in Tables 4 and 5, respectively. In both disease groups, higher GSE scores were independently associated with higher SOC total scores. The contribution of GSE to the variance of SOC total was similar in both UC and CD. In contrast, higher FSS5 scores were independently associated with lower SOC total scores. Neither in UC nor in CD, the sociodemographic and 
TABLE 1: Characteristics of patients with ulcerative colitis $(n=190)$ and Crohn's disease $(n=238)$.

\begin{tabular}{|c|c|c|c|}
\hline Characteristics & UC & $\mathrm{CD}$ & $P$ value \\
\hline \multicolumn{4}{|l|}{ Sociodemographic characteristics } \\
\hline Age, median (range) & $41(20-79)$ & $38(18-75)$ & 0.019 \\
\hline Female gender $(n, \%)$ & $82(43)$ & $130(55)$ & 0.018 \\
\hline Education > 12 years $(n, \%)$ & $92(49)$ & $108(46)$ & 0.558 \\
\hline Work status $=$ working $/$ student $(n, \%)$ & $134(71)$ & $148(62)$ & 0.064 \\
\hline Marital status $=$ married $/$ cohabitating $(n, \%)$ & $149(78)$ & $160(67)$ & 0.012 \\
\hline Current smoking, yes $(n, \%)$ & $15(8)$ & $65(27)$ & $<0.001$ \\
\hline \multicolumn{4}{|l|}{ Disease-related characteristics } \\
\hline Disease duration in years, median (range) & $6(0.2-45)$ & $11(0.1-44)$ & $<0.001$ \\
\hline HBAI median (range) & & $5(0-30)$ & \\
\hline SCCAI median (range) & $4(0-15)$ & & \\
\hline Previous surgery for IBD $(n, \%)$ & $13(7)$ & $130(55)$ & $<0.001$ \\
\hline Comorbidities, yes $(n, \%)$ & $84(45)$ & $88(37)$ & 0.137 \\
\hline Adverse drug reaction, yes $(n, \%)$ & $107(57)$ & $142(60)$ & 0.487 \\
\hline
\end{tabular}

Abbreviations: UC: ulcerative colitis; CD: Crohn's disease; HBAI: Harvey-Bradshaw activity index; SCCAI: simple clinical colitis activity index. Continuous variables were assessed by the Mann-Whitney $U$ test. Chi-squared test $\left(\chi^{2}\right)$ was used to compare proportions.

TABLE 2: SOC, FSS-5, and GSE scores in patients with ulcerative colitis and Crohn's disease.

\begin{tabular}{|c|c|c|c|c|}
\hline Ulcerative colitis & All $(n=190)$ & Women $(n=82)$ & $\operatorname{Men}(n=108)$ & $P$ value* \\
\hline Total SOC score, mean (SD) & $66.74(11.75)$ & $66.32(11.51)$ & $67.06(11.97)$ & 0.665 \\
\hline Comprehensibility & $19.33(3.88)$ & $24.29(5.36)$ & $24.28(5.61)$ & 0.985 \\
\hline Manageability & $25.58(5.52)$ & $20.34(3.70)$ & $20.84(4.07)$ & 0.383 \\
\hline Meaningfulness & $21.83(4.04)$ & $21.68(4.05)$ & $21.94(4.05)$ & 0.660 \\
\hline FSS-5, mean (SD) & $4.13(1.54)$ & $4.37(1.62)$ & $3.95(1.45)$ & 0.063 \\
\hline GSE, mean (SD) & $30.04(5.55)$ & $28.67(5.53)$ & $31.07(5.37)$ & 0.003 \\
\hline Crohn's disease & All $(n=238)$ & Women $(n=130)$ & $\operatorname{Men}(n=108)$ & $P$ value* \\
\hline Total SOC score, mean (SD) & $65.85(11.25)$ & $64.96(11.45)$ & $66.92(10.96)$ & 0.182 \\
\hline Comprehensibility & $19.30(3.93)$ & $24.15(5.26)$ & $25.09(4.95)$ & 0.160 \\
\hline Manageability & $25.48(5.25)$ & $19.58(4.05)$ & $20.95(3.71)$ & 0.007 \\
\hline Meaningfulness & $21.07(4.07)$ & $21.23(4.06)$ & $20.87(4.10)$ & 0.498 \\
\hline FSS-5 mean (SD) & $4.49(1.48)$ & $4.68(1.55)$ & $4.26(1.36)$ & 0.031 \\
\hline GSE mean (SD) & $29.40(5.44)$ & $29.23(5.88)$ & $29.61(4.89)$ & 0.601 \\
\hline
\end{tabular}

Abbreviations: SOC: Sense of Coherence; FSS-5: Five-Item Fatigue Severity Scale; GSE: General Self-Efficacy Scale.

${ }^{*} P$ values estimated between women and men by independent sample $t$-test.

disease-related variables were significantly associated with SOC total when controlling for FSS-5 and GSE.

Higher GSE scores were independently associated with higher sub-dimension scores in both the UC and CD groups. In UC, FSS-5 was negatively associated with lower scores at all three subdimensions. In CD, FSS-5 was negatively associated with manageability and meaningfulness. FSS-5 explained more of the total variance of the subdimensions in the UC group compared to the CD group. After controlling for FSS-5 and GSE scores, neither sociodemographic variables nor disease-related variables were associated with SOC subdimensional scores.

\section{Discussion}

The aim of this study was to explore associations between sociodemographic and disease-related variables, fatigue interference, self-efficacy, and SOC total and its subdimensions in IBD patients. No significant differences were found in SOC scores between UC and CD patients. The key finding was that self-efficacy had a strong positive association with SOC, whereas fatigue interference had a strong negative association with SOC after controlling for sociodemographic and disease-related variables.

The SOC-13 instrument has been used in a number of studies, including both general and various chronic disease populations [15]. Few studies have investigated SOC in IBD patients $[19,43-46]$ and only two studies used the SOC13 scale $[43,44]$. We found the mean SOC total score for our IBD patients (66.25) to be comparable with estimates of Swedish IBD patients (69.00) [43] and higher than that in Japanese IBD patients (53.84) [44]. In addition, our results were comparable with estimated mean SOC total score at about 70.00 in the general population $[15,47]$. 
TABLE 3: Bivariate correlations (Pearson's $r$ ) between age, disease activity scores, disease duration, fatigue interference, self-efficacy, and SOC in ulcerative colitis and Crohn's disease patients.

\begin{tabular}{|c|c|c|c|c|}
\hline & SOC total & Comprehensibility & Manageability & Meaningfulness \\
\hline \multicolumn{5}{|l|}{ Ulcerative colitis $(n=190)$} \\
\hline Age in years & 0.01 & 0.02 & -0.07 & 0.06 \\
\hline SCCAI & -0.15 & $-0.19^{\mathrm{a}}$ & -0.13 & -0.05 \\
\hline Disease duration in years & 0.07 & 0.11 & 0.00 & 0.04 \\
\hline FSS-5 & $-0.48^{\mathrm{b}}$ & $-0.50^{\mathrm{b}}$ & $-0.40^{\mathrm{b}}$ & $-0.33^{\mathrm{b}}$ \\
\hline GSE & $0.51^{\mathrm{b}}$ & $0.46^{\mathrm{b}}$ & $0.47^{\mathrm{b}}$ & $0.41^{\mathrm{b}}$ \\
\hline \multicolumn{5}{|l|}{ Crohn's disease $(n=238)$} \\
\hline Age in years & 0.11 & 0.11 & 0.07 & 0.09 \\
\hline HBAI & -0.17 & -0.12 & $-0.17^{\mathrm{a}}$ & -0.14 \\
\hline Disease duration in years & 0.09 & 0.06 & 0.06 & 0.11 \\
\hline FSS-5 & $-0.42^{\mathrm{b}}$ & $-0.28^{\mathrm{b}}$ & $-0.36^{\mathrm{b}}$ & $-0.44^{\mathrm{b}}$ \\
\hline GSE & $0.48^{\mathrm{b}}$ & $0.42^{\mathrm{b}}$ & $0.38^{\mathrm{b}}$ & $0.45^{\mathrm{b}}$ \\
\hline
\end{tabular}

Abbreviations: SCCAI: simple clinical colitis activity index; HBAI: Harvey-Bradshaw activity index; FSS-5: Five-Item Fatigue Severity Scale; GSE: General SelfEfficacy Scale.

${ }^{\mathrm{a}} P<0.01,{ }^{\mathrm{b}} P<0.001$.

TABLE 4: Four independent linear regression analyses with SOC total and subdimension scores as dependent variables in patients with ulcerative colitis $(n=190)$.

\begin{tabular}{|c|c|c|c|c|c|c|c|c|}
\hline \multirow{2}{*}{ Independent variables } & \multicolumn{2}{|c|}{ SOC total score } & \multicolumn{2}{|c|}{ Comprehensibility } & \multicolumn{2}{|c|}{ Manageability } & \multicolumn{2}{|c|}{ Meaningfulness } \\
\hline & $\beta$ & $P$ value & $\beta$ & $P$ value & $\beta$ & $P$ value & $\beta$ & $P$ value \\
\hline \multicolumn{9}{|l|}{ Step 1.} \\
\hline Gender $($ female $=0)$ & -0.13 & 0.030 & -0.15 & 0.021 & -0.08 & 0.219 & -0.08 & 0.211 \\
\hline Age & 0.00 & 0.998 & -0.01 & 0.527 & -0.06 & 0.328 & 0.06 & 0.388 \\
\hline Education level $(\leq 12$ years $=0)$ & & & 0.07 & 0.233 & & & & \\
\hline Work status (not working $=0$ ) & & & -0.01 & 0.677 & & & & \\
\hline Marital status (not married/cohabitating $=0$ ) & 0.14 & 0.021 & 0.11 & 0.100 & 0.10 & 0.111 & 0.16 & 0.018 \\
\hline Explained variance $\left(R^{2}\right)$ & $6.2 \%$ & & $7.0 \%$ & & $4.8 \%$ & & $6.2 \%$ & \\
\hline \multicolumn{9}{|l|}{ Step 2.} \\
\hline SCCAI & -0.02 & 0.744 & -0.06 & 0.311 & -0.02 & 0.814 & & \\
\hline Comorbidities $($ no $=0)$ & -0.03 & 0.638 & & & -0.03 & 0.624 & & \\
\hline$R^{2}$ change & $2.9 \%$ & & $2.9 \%$ & & $2.2 \%$ & & $0.01 \%$ & \\
\hline \multicolumn{9}{|l|}{ Step 3.} \\
\hline FSS-5 & -0.40 & $<0.001$ & -0.42 & $<0.001$ & -0.33 & $<0.001$ & -0.25 & $<0.001$ \\
\hline$R^{2}$ change & $19.0 \%$ & & $20.1 \%$ & & $13.3 \%$ & & $9.3 \%$ & \\
\hline \multicolumn{9}{|l|}{ Step 4.} \\
\hline GSE & 0.44 & $<0.001$ & 0.39 & $<0.001$ & 0.39 & $<0.001$ & 0.36 & $<0.001$ \\
\hline$R^{2}$ change & $16.0 \%$ & & $13.0 \%$ & & $13.6 \%$ & & $11.5 \%$ & \\
\hline Total $R^{2}$ & $44.8 \%$ & & $43.0 \%$ & & $33.8 \%$ & & $27.0 \%$ & \\
\hline
\end{tabular}

Abbreviations: $\beta$ : standardized beta coefficient; SCCAI: simple clinical colitis activity index; FSS-5: Five-Item Fatigue Severity Scale; GSE: General Self-Efficacy Scale.

In addition to gender and age, variables that had a Pearson correlation coefficient with $P<0.10$ in bivariate analyses were included in final regression models.

We found, in accordance with other studies, a strong correlation between high self-efficacy and high SOC [31, $48,49]$. Both SOC and self-efficacy have been found to be positively correlated with characteristics such as high selfesteem, internal locus of control, achievement motivation, self-control, optimism, and satisfaction [12, 31, 35]. Hence, SOC and self-efficacy are personal resources important to promote health $[11,24]$. According to Antonovsky, SOC is a dispositional orientation; a person with a strong SOC is more likely than a person with a weak SOC to define a stimulus as a nonstressor because he/she is confident that things will work out well [11]. A systematic review supported this hypothesis; the stronger the SOC, the less the symptoms and distress [12]. Self-efficacy influences people's choices and behavior [35] and accordingly may be an important resource needed to strengthen SOC.

The FSS- 5 measures the degree to which fatigue interferes with physical functioning and activities of daily living. In 
TABLE 5: Four independent linear regression analyses with SOC total and subdimension scores as dependent variables in patients with Crohn's disease $(n=238)$.

\begin{tabular}{|c|c|c|c|c|c|c|c|c|}
\hline \multirow{2}{*}{ Independent variables } & \multicolumn{2}{|c|}{ SOC total score } & \multicolumn{2}{|c|}{ Comprehensibility } & \multicolumn{2}{|c|}{ Manageability } & \multicolumn{2}{|c|}{ Meaningfulness } \\
\hline & $\beta$ & $P$ value & $\beta$ & $P$ value & $\beta$ & $P$ value & $\beta$ & $P$ value \\
\hline \multicolumn{9}{|l|}{ Step 1.} \\
\hline Gender $($ female $=0)$ & 0.05 & 0.425 & 0.06 & 0.336 & 0.14 & 0.023 & -0.09 & 0.103 \\
\hline Age in years & 0.11 & 0.070 & 0.11 & 0.096 & 0.06 & 0.359 & 0.06 & 0.333 \\
\hline Education level $(\leq 12$ years $=0)$ & 0.09 & 0.144 & 0.04 & 0.590 & 0.13 & 0.045 & 0.07 & 0.251 \\
\hline Work status (not working $=0$ ) & & & & & -0.03 & 0.666 & 0.01 & 0.859 \\
\hline Marital status (not married/cohabitating $=0$ ) & 0.10 & 0.090 & 0.09 & 0.174 & 0.14 & 0.023 & & \\
\hline Current smoker $($ no $=0)$ & -0.06 & 0.305 & & & -0.03 & 0.643 & -0.11 & 0.063 \\
\hline Explained variance $\left(R^{2}\right)$ & $9.1 \%$ & & $4.7 \%$ & & $11.3 \%$ & & $8.7 \%$ & \\
\hline \multicolumn{9}{|l|}{ Step 2.} \\
\hline HBAI & 0.00 & 0.990 & -0.01 & 0.866 & -0.01 & 0.856 & 0.02 & 0.694 \\
\hline Disease duration in years & & & & & & & 0.08 & 0.186 \\
\hline Adverse drug reaction $($ no $=0)$ & -0.08 & 0.157 & -0.11 & 0.075 & -0.10 & 0.104 & & \\
\hline$R^{2}$ change & $3.1 \%$ & & $2.3 \%$ & & $2.8 \%$ & & $2.3 \%$ & \\
\hline \multicolumn{9}{|l|}{ Step 3.} \\
\hline FSS-5 & -0.31 & $<0.001$ & -0.17 & 0.012 & -0.26 & $<0.001$ & -0.38 & $<0.001$ \\
\hline$R^{2}$ change & $11.2 \%$ & & $4.8 \%$ & & $7.4 \%$ & & $15.3 \%$ & \\
\hline \multicolumn{9}{|l|}{ Step 4.} \\
\hline GSE & 0.42 & $<0.001$ & 0.39 & $<0.001$ & 0.31 & $<0.001$ & 0.36 & $<0.001$ \\
\hline$R^{2}$ change & $15.9 \%$ & & $14.2 \%$ & & $8.7 \%$ & & $11.9 \%$ & \\
\hline Total $R^{2}$ & $39.3 \%$ & & $26.0 \%$ & & $30.3 \%$ & & $38.2 \%$ & \\
\hline
\end{tabular}

Abbreviations: $\beta$ : standardized beta coefficient; HBAI: Harvey-Bradshaw activity index; FSS-5: Five-Item Fatigue Severity Scale; GSE: General Self-Efficacy Scale.

In addition to gender and age, variables that had a Pearson correlation coefficient with $P<0.10$ in bivariate analyses were included in final regression models.

the current study, higher FSS-5 scores were found to be negatively associated with SOC. Fatigue has been described elsewhere by IBD patients to impact on thoughts and daily management and to create feelings of "not wanting to bother with anything" [22, 50]. These descriptions indicate that personal resources may impact on management of fatigue in daily living. Fatigue has also been found to have a negative impact on HRQoL and to be related to poor sleep quality, anxiety, depression, and stress in IBD patients [5053]. These results may indicate that fatigue strongly impacts IBD patients' health and well-being. However, as our study had a cross-sectional design, we were unable to identify the direction of the associations between fatigue interference and SOC. The amount of variance in SOC explained by fatigue interference was higher in the UC group compared to the CD group. In UC, the subdimensions comprehensibility and manageability were most affected by fatigue interference. These dimensions refer to that a situation is perceived as understandable and resources to deal with the situation are available. We could not control for psychosocial factors such as psychological distress and poor sleep quality and cannot exclude that the relationships between SOC and fatigue were confounded with such factors.

Disease activity scores were negatively associated with SOC in the bivariate analyses but not in the multivariate analyses. The unpredictable nature of IBD may be important to consider when assessing the relationship between disease activity and psychosocial factors. Because the symptoms of IBD are fluctuating, a timeframe of the last twenty-four hours in the HBAI and the SCCAI may be a limitation when using cross-sectional data. Further, manifestations such as fecal inconsistency and urgency may reinforce the experience of "uncontrollability" of the disease. These manifestations are found to limit the sense of control over social, working, and personal lives for IBD patients [54]. A negative association between current disease symptoms and HRQoL has previously been reported in IBD patients $[6-8,55,56]$. It has been noted in systematic reviews of other chronic conditions that SOC may serve as a mediator between stressors and HRQoL, with a higher SOC being associated with increased HRQoL scores [14]. Hence, the nature of the relationship between SOC, disease symptoms, and HRQoL needs additional investigation in future longitudinal studies within IBD populations.

We found no significant association between sociodemographic variables and SOC scores after controlling for disease-related variables, fatigue interference, and selfefficacy in our study. Contrary to these results, a systematic review on SOC research concluded that SOC total scores tend to increase with age and that men tend to have a higher SOC score than women [15]. Since the patients were recruited from outpatient clinics at hospitals, our results may not be replicable in a population-based cohort of IBD patients. In the theory of SOC, family life, work, and educational 
attainment are seen as "resistance resources" that contribute to the development of SOC [11]. In previous studies, the quality of the relationship with partner, quality of paid work, and social support has been found to be strongly associated with SOC $[12,18]$. In qualitative interviews, $C D$ patients have expressed that important resources were social support, job satisfaction, and occupational balance [57]. We did not include questions about the quality of the family life and of paid work.

In this study, we also explored the three subdimensions comprehensibility, manageability, and meaningfulness. The bivariate analyses revealed that some of the sociodemographic and disease-related variables were correlated with the SOC subdimensions. Although these associations were not statistically significant in the multivariate analysis, the findings are of interest from a clinical point of view. Antonovsky claimed that the three SOC subdimensions are interrelated and dynamic [11]. This means that a patient with a low SOC total score may have a high score on one or two subdimensions. In clinical setting this is important. Including the patient in the interpretation of the SOC sub-dimension scores where the patient gives meaning to the scores in view of his/her life situation and resources available may lead to that the patients are able to improve an unsatisfactory situation $[47,58]$. Studies of chronic diseases have reported significant changes in SOC scores and improved coping as results of interventions based on salutogenic treatment principles [16, 59].

In conclusion, in both UC and CD, higher self-efficacy had a positive association with SOC, whereas fatigue interference was negatively associated with SOC. Longitudinal studies are warranted to investigate the value of SOC as predictor of disability, medication adherence, HRQoL, and coping behavior in IBD patients.

\section{Conflict of Interests}

The authors have no conflict of interests to report.

\section{Acknowledgments}

The authors thank the following persons for including patients in the study: Elisabeth Finnes Strøm, Turid Bua, Gunnhild Seim, and Elisabeth Haugen, Oslo University Hospital, Oslo; Ellen Vogt, Diakonhjemmet Hospital, Oslo; Magne Henriksen, Kjersti Eek, and Elisabeth Hansen, Østfold Hospital Trust, Fredrikstad, Sarpsborg, and Moss; Roald Torp and Øystein Hovde, Innlandet Hospital Trust, Hamar and Gjøvik; Trygve Hausken, Haukeland University Hospital, Bergen; Ole Høie, Jenny Nornes, and Heidi Solhaug, Southern Hospital Trust, Arendal and Kristiansand; Nina Lindheim, Telemark Hospital Trust, Skien; Venke Ekornseter Knutsen, Health Fonna, Haugesund; and Inger Johanne $\mathrm{B} \emptyset$, Stavanger University Hospital. They also thank Milada Cvancarova, University of Oslo, for statistical guidance, and Ferring Pharmaceuticals for their practical and financial help with preparation of the study. This study was funded in part by Ferring Pharmaceuticals.

\section{References}

[1] J. Burisch, T. Jess, M. Martinato, and P. L. Lakatos, "The burden of inflammatory bowel disease in Europe," Journal of Crohn's Colitis, vol. 7, no. 4, pp. 322-337, 2013.

[2] I. C. Solberg, I. Lygren, J. Jahnsen et al., "Clinical course during the first 10 years of ulcerative colitis: results from a populationbased inception cohort (IBSEN Study)," Scandinavian Journal of Gastroenterology, vol. 44, no. 4, pp. 431-440, 2009.

[3] I. C. Solberg, M. H. Vatn, O. Høie et al., "Clinical course in Crohn's disease: results of a Norwegian population-based tenyear follow-up study," Clinical Gastroenterology and Hepatology, vol. 5, no. 12, pp. 1430-1438, 2007.

[4] L. A. Graff, J. R. Walker, I. Clara et al., "Stress coping, distress, and health perceptions in inflammatory bowel disease and community controls," The American Journal of Gastroenterology, vol. 104, no. 12, pp. 2959-2969, 2009.

[5] K. Larsson, L. Lööf, A. Rönnblom, and K. Nordin, "Quality of life for patients with exacerbation in inflammatory bowel disease and how they cope with disease activity," Journal of Psychosomatic Research, vol. 64, no. 2, pp. 139-148, 2008.

[6] M. L. Høivik, T. Bernklev, I. C. Solberg et al., "Patients with Crohn's disease experience reduced general health and vitality in the chronic stage: Ten-year results from the IBSEN study," Journal of Crohn's and Colitis, vol. 6, no. 4, pp. 441-453, 2012.

[7] T. Bernklev, J. Jahnsen, E. Aadland et al., "Health-related quality of life in patients with inflammatory bowel disease five years after the initial diagnosis," Scandinavian Journal of Gastroenterology, vol. 39, no. 4, pp. 365-373, 2004.

[8] K. Nordin, L. Påhlman, K. Larsson, M. Sundberg-Hjelm, and L. Lööf, "Health-related quality of life and psychological distress in a population-based sample of Swedish patients with inflammatory bowel disease," Scandinavian Journal of Gastroenterology, vol. 37, no. 4, pp. 450-457, 2002.

[9] M. L. Hoivik, B. Moum, I. C. Solberg et al., "Health-related quality of life in patients with ulcerative colitis after a 10-year disease course: results from the IBSEN study," Gut, vol. 62, no. 3, pp. 368-375, 2013.

[10] I. van der Eijk, I. G. Vlachonikolis, P. Munkholm et al., "The role of quality of care in health-related quality of life in patients with IBD," Inflammatory Bowel Diseases, vol. 10, no. 4, pp. 392-398, 2004.

[11] A. Antonovsky, Unravelling the Mystery of Health: How People Manage Stress and Stay Well, Jossey-Bass, San Francisco, Calif, USA, 1987.

[12] M. Eriksson and B. Lindström, "Antonovsky's sense of coherence scale and the relation with health: a systematic review," Journal of Epidemiology and Community Health, vol. 60, no. 5, pp. 376-381, 2006.

[13] B. Silarova, I. Nagyova, J. Rosenberger et al., "Sense of coherence as an independent predictor of health-related quality of life among coronary heart disease patients," The European Journal of Cardiovascular Nursing, 2013.

[14] M. Eriksson and B. Lindström, "Antonovsky's sense of coherence scale and its relation with quality of life: a systematic review," Journal of Epidemiology and Community Health, vol. 61, no. 11, pp. 938-944, 2007.

[15] M. Eriksson and B. Lindström, "Validity of Antonovsky's sense of coherence scale: a systematic review," Journal of Epidemiology and Community Health, vol. 59, no. 6, pp. 460-466, 2005.

[16] E. Langeland, T. Riise, B. R. Hanestad, M. W. Nortvedt, K. Kristoffersen, and A. K. Wahl, "The effect of salutogenic 
treatment principles on coping with mental health problems. a randomised controlled trial," Patient Education and Counseling, vol. 62, no. 2, pp. 212-219, 2006.

[17] C. Cederfjäll, A. Langius-Eklöf, K. Lidman, and R. Wredling, "Self-reported adherence to antiretroviral treatment and degree of sense of coherence in a group of HIV-infected patients," AIDS Patient Care and STDs, vol. 16, no. 12, pp. 609-616, 2002.

[18] S.-M. Volanen, E. Lahelma, K. Silventoinen, and S. Suominen, "Factors contributing to sense of coherence among men and women," The European Journal of Public Health, vol. 14, no. 3, pp. 322-330, 2004.

[19] L. Oxelmark, A. Magnusson, R. Löfberg, and P. Hillerås, "Group-based intervention program in inflammatory bowel disease patients: effects on quality of life," Inflammatory Bowel Diseases, vol. 13, no. 2, pp. 182-190, 2007.

[20] J. Casati, B. B. Toner, E. C. de Rooy, D. A. Drossman, and R. G. Maunder, "Concerns of patients with inflammatory bowel disease: a review of emerging themes," Digestive Diseases and Sciences, vol. 45, no. 1, pp. 26-31, 2000.

[21] H. Stjernman, C. Tysk, S. Almer, M. Ström, and H. Hjortswang, "Worries and concerns in a large unselected cohort of patients with Crohn's disease," Scandinavian Journal of Gastroenterology, vol. 45, no. 6, pp. 696-706, 2010.

[22] W. Czuber-Dochan, L. B. Dibley, H. Terry, E. Ream, and C. Norton, "The experience of fatigue in people with inflammatory bowel disease: an exploratory study," Journal of Advanced Nursing, vol. 69, no. 9, pp. 1987-1999, 2013.

[23] L. B. Krupp, "Fatigue in multiple sclerosis: definition, pathophysiology and treatment," CNS Drugs, vol. 17, no. 4, pp. 225$234,2003$.

[24] A. Bandura, "Health promotion by social cognitive means," Health Education and Behavior, vol. 31, no. 2, pp. 143-164, 2004.

[25] R. S. Lazarus and S. Folkman, Stress, Appraisal, and Coping, Springer, New York, NY, USA, 1984.

[26] M. S. Silverberg, J. Satsangi, T. Ahmad, I. D. Arnott, C. N. Bernstein, and S. R. Brant, "Toward an integrated clinical, molecular and serological classification of inflammatory bowel disease: report of a working party of the 2005 Montreal world congress of gastroenterology," The Canadian Journal of Gastroenterology, vol. 19, supplement A, pp. 5-36, 2005.

[27] R. F. Harvey and J. M. Bradshaw, "A simple index of Crohn'sdisease activity," The Lancet, vol. 315, no. 8167, p. 514, 1980.

[28] R. S. Walmsley, R. C. S. Ayres, R. E. Pounder, and R. N. Allan, "A simple clinical colitis activity index," Gut, vol. 43, no. 1, pp. 29-32, 1998.

[29] F. Guillemin, C. Bombardier, and D. Beaton, "Cross-cultural adaptation of health-related quality of life measures: literature review and proposed guidelines," Journal of Clinical Epidemiology, vol. 46, no. 12, pp. 1417-1432, 1993.

[30] J. B. Hittner, "Factorial invariance of the 13-item Sense of Coherence scale across gender," Journal of Health Psychology, vol. 12, no. 2, pp. 273-280, 2007.

[31] A. Lerdal, R. Andenæs, E. Bjørnsborg et al., "Personal factors associated with health-related quality of life in persons with morbid obesity on treatment waiting lists in Norway," Quality of Life Research, vol. 20, no. 8, pp. 1187-1196, 2011.

[32] P. M. Fayers and D. Machin, Quality of Life: The Assessment, Analysis, and Interpretation of Patient-Reported Outcomes, John Wiley \& Sons, Chichester, UK, 2nd edition, 2007.

[33] R. Schwarzer and M. Jerusalem, "Generalized self-efficacy scale," in Measures in Health Psychology: A User's Portfolio, J.
Weinman, S. Wright, and M. Johnston, Eds., pp. 35-37, NFER Nelson, Windsor, UK, 1995.

[34] E. Røysamb, R. Schwarzer, and M. Jerusalem, "The general self-efficacy scale," 2013, http://userpage.fu-berlin.de/ health/ selfscal.htm.

[35] A. Leganger, P. Kraft, and E. Røysamb, "Perceived self-efficacy in health behaviour research: conceptualisation, measurement and correlates," Psychology \& Health, vol. 15, no. 1, pp. 51-69, 2000.

[36] T. Bonsaksen, A. Lerdal, and M. S. Fagermoen, "Factors associated with self-efficacy in persons with chronic illness," The Scandinavian Journal of Psychology, vol. 53, no. 4, pp. 333-339, 2012.

[37] R. J. Mills, C. A. Young, R. S. Nicholas, J. F. Pallant, and A. Tennant, "Rasch analysis of the Fatigue Severity Scale in multiple sclerosis," Multiple Sclerosis, vol. 15, no. 1, pp. 81-87, 2009.

[38] L. Whitehead, "The measurement of fatigue in chronic illness: a systematic review of unidimensional and multidimensional fatigue measures," Journal of Pain and Symptom Management, vol. 37, no. 1, pp. 107-128, 2009.

[39] A. Lerdal, A. K. Wahl, T. Rustøen, B. R. Hanestad, T. Moum, and P. Bjerregaard, "Fatigue in the general population: a translation and test of the psychometric properties of the Norwegian version of the fatigue severity scale," Scandinavian Journal of Public Health, vol. 33, no. 2, pp. 123-130, 2005.

[40] A. Lerdal, S. Johansson, A. Kottorp, and K. L. Von, "Psychometric properties of the fatigue severity scale: rasch analyses of responses in a Norwegian and a Swedish MS cohort," Multiple Sclerosis, vol. 16, no. 6, pp. 733-741, 2010.

[41] L. J. Cronbach, Essentials of Psychological Testing, Harper \& Row, New York, NY, USA, 5th edition, 1990.

[42] I. SPSS, "SPSS for windows (version 20)," Chicago, Ill, USA, 2010.

[43] M. Bengtsson, K. Sjoberg, M. Candamio, A. Lerman, and B. Ohlsson, "Anxiety in close relationships is higher and self-esteem lower in patients with irritable bowel syndrome compared to patients with inflammatory bowel disease," The European Journal of Internal Medicine, vol. 24, no. 3, pp. 266272, 2013.

[44] T. Kuroki, A. Ohta, R. Sherriff-Tadano et al., "Imbalance in the stress-adaptation system in patients with inflammatory bowel disease," Biological Research for Nursing, vol. 13, no. 4, pp. 391398, 2011.

[45] M. Siassi, M. Weiss, W. Hohenberger, F. Lösel, and K. Matzel, "Personality rather than clinical variables determines quality of life after major colorectal surgery," Diseases of the Colon \& Rectum, vol. 52, no. 4, pp. 662-668, 2009.

[46] L. Oxelmark, G. Nordström, U. Sjöqvist, and R. Löfberg, "Anxiety, functional health status, and coping ability in patients with ulcerative colitis who are undergoing colonoscopic surveillance," Inflammatory Bowel Diseases, vol. 10, no. 5, pp. 612-617, 2004.

[47] U. Lindmark, U. Stenström, E. W. R. Gerdin, and A. Hugoson, "The distribution of "sense of coherence" among Swedish adults: a quantitative cross-sectional population study," Scandinavian Journal of Public Health, vol. 38, no. 1, pp. 1-8, 2010.

[48] H. Kroninger-Jungaberle and D. Grevenstein, "Development of salutogenetic factors in mental health-Antonovsky's sense of coherence and Bandura's self-efficacy related to Derogatis' symptom check list (SCL-90-R)," Health and Quality of Life Outcomes, vol. 11, no. 1, p. 80, 2013. 
[49] T. L. Smith and L. S. Meyers, "The sense of coherence: its relationship to personality, stress, and health measures," Journal of Social Behavior and Personality, vol. 12, no. 2, pp. 513-526, 1997.

[50] W. Czuber-Dochan, E. Ream, and C. Norton, "Review article: description and management of fatigue in inflammatory bowel disease," Alimentary Pharmacology and Therapeutics, vol. 37, no. 5, pp. 505-516, 2013.

[51] Y. Bol, A. A. Duits, C. E. R. Vertommen-Mertens et al., "The contribution of disease severity, depression and negative affectivity to fatigue in multiple sclerosis: a comparison with ulcerative colitis," Journal of Psychosomatic Research, vol. 69, no. 1, pp. 43-49, 2010.

[52] L. A. Graff, N. Vincent, J. R. Walker et al., "A population-based study of fatigue and sleep difficulties in inflammatory bowel disease," Inflammatory Bowel Diseases, vol. 17, no. 9, pp. 18821889, 2011.

[53] L. A. Graff, I. Clara, J. R. Walker, L. Lix, R. Carr, and N. Miller, "Changes in fatigue over 2 years are associated with activity of inflammatory bowel disease and psychological factors," Clinical Gastroenterology and Hepatology, vol. 11, no. 9, pp. 1140-1146, 2013.

[54] L. Dibley and C. Norton, "Experiences of fecal incontinence in people with inflammatory bowel disease: self-reported experiences among a community sample," Inflammatory Bowel Diseases, vol. 19, no. 7, pp. 1450-1462, 2013.

[55] L. A. Graff, J. R. Walker, L. Lix et al., "The relationship of inflammatory bowel disease type and activity to psychological functioning and quality of life," Clinical Gastroenterology and Hepatology, vol. 4, no. 12, pp. 1491-1501, 2006.

[56] L. M. Lix, L. A. Graff, J. R. Walker et al., "Longitudinal study of quality of life and psychological functioning for active, fluctuating, and inactive disease patterns in inflammatory bowel disease," Inflammatory Bowel Diseases, vol. 14, no. 11, pp. 15751584, 2008.

[57] M. Dür, M. Sadlonova, S. Haider, A. Binder, M. Stoffer, and M. Coenen, "Health determining concepts important to people with Crohn's disease and their coverage by patient-reported outcomes of health and wellbeing," Journal of Crohn's and Colitis, 2013.

[58] A. Antonovsky, "The salutogenic model as a theory to guide health promotion," Health Promotion International, vol. 11, no. 1, pp. 11-18, 1996.

[59] M. Sack, H. W. Künsebeck, and F. Lamprecht, "[Sense of coherence and psychosomatic treatment outcome. an empirical study of salutogenesis]," Psychotherapie, Psychosomatic, Medizinische Psychologie, vol. 47, no. 5, pp. 149-155, 1997. 


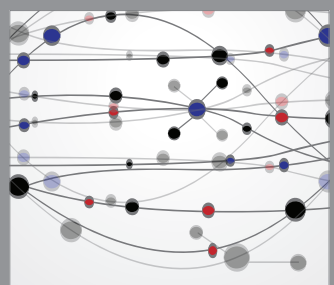

The Scientific World Journal
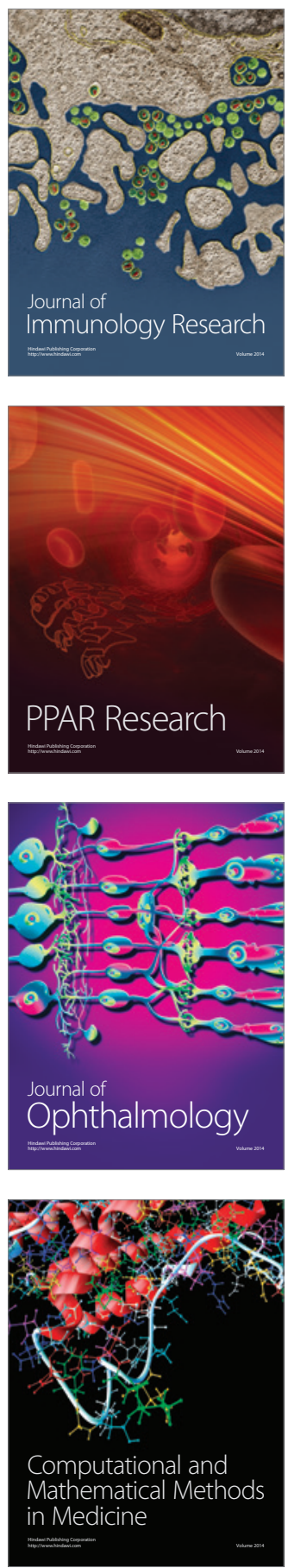

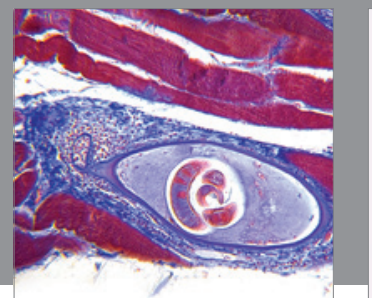

Gastroenterology

Research and Practice
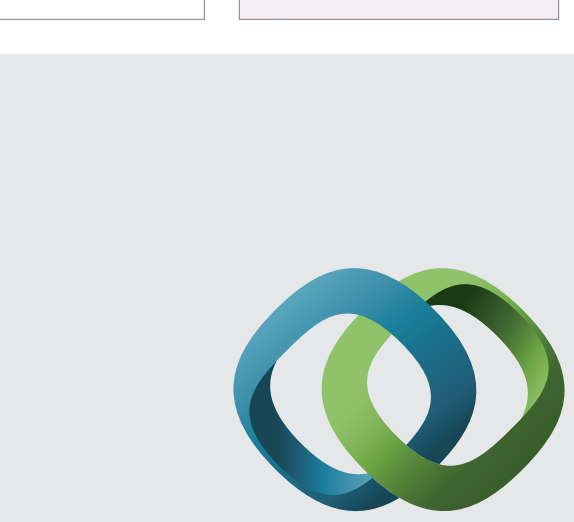

\section{Hindawi}

Submit your manuscripts at

http://www.hindawi.com
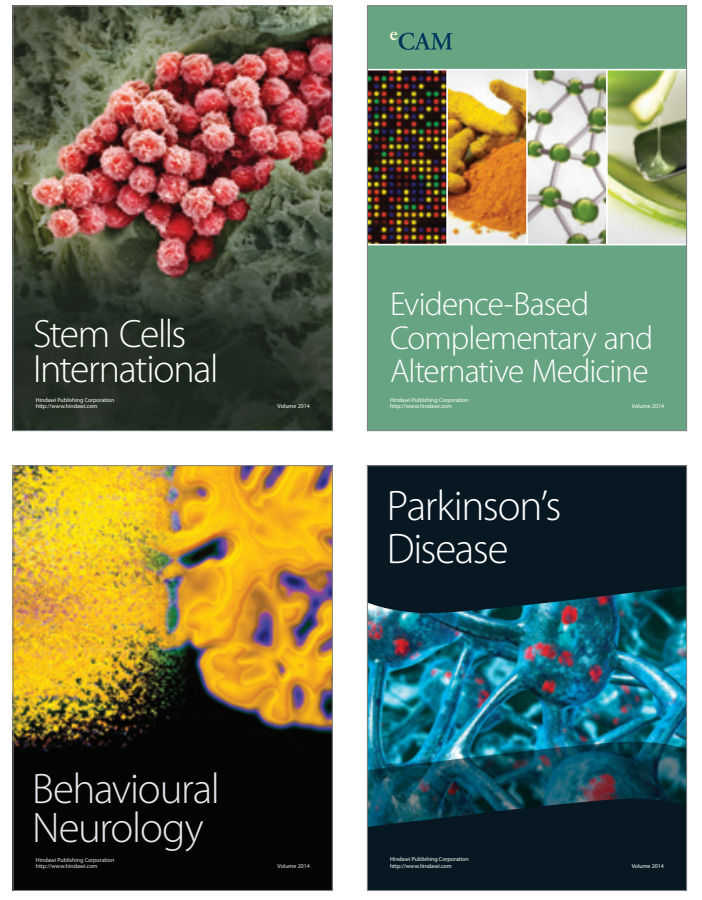
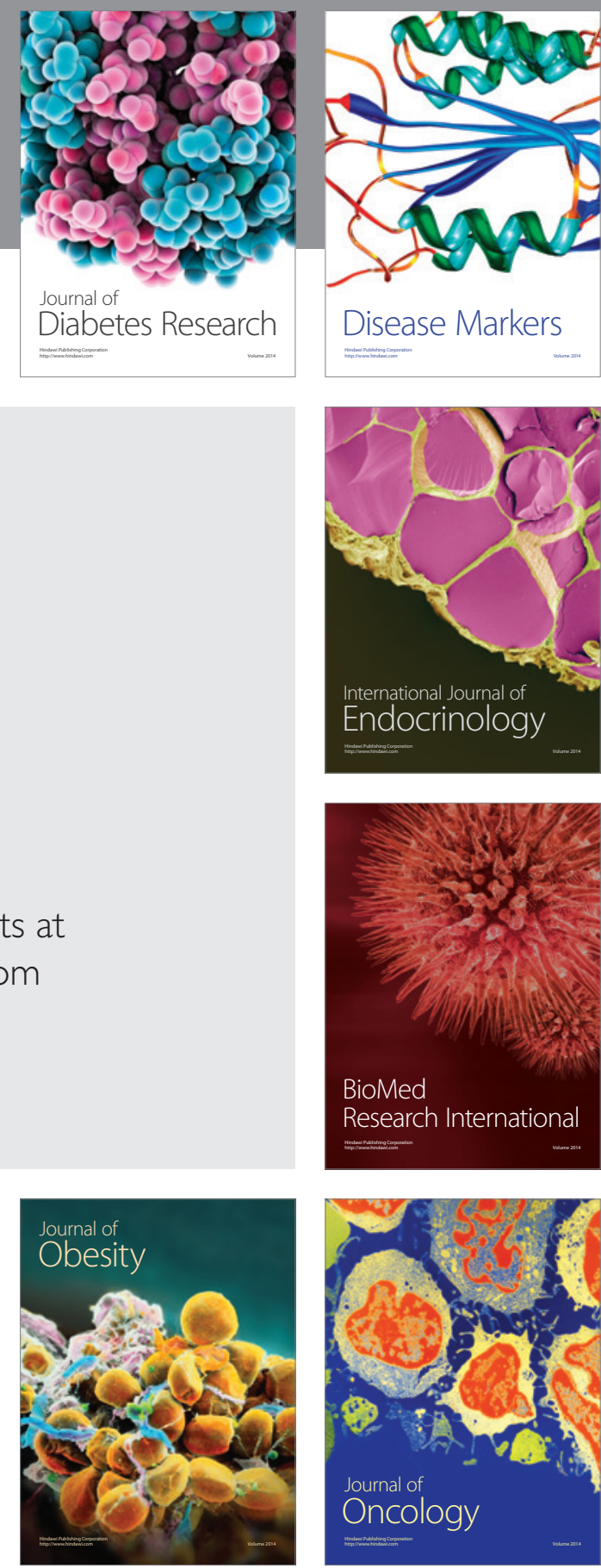

Disease Markers
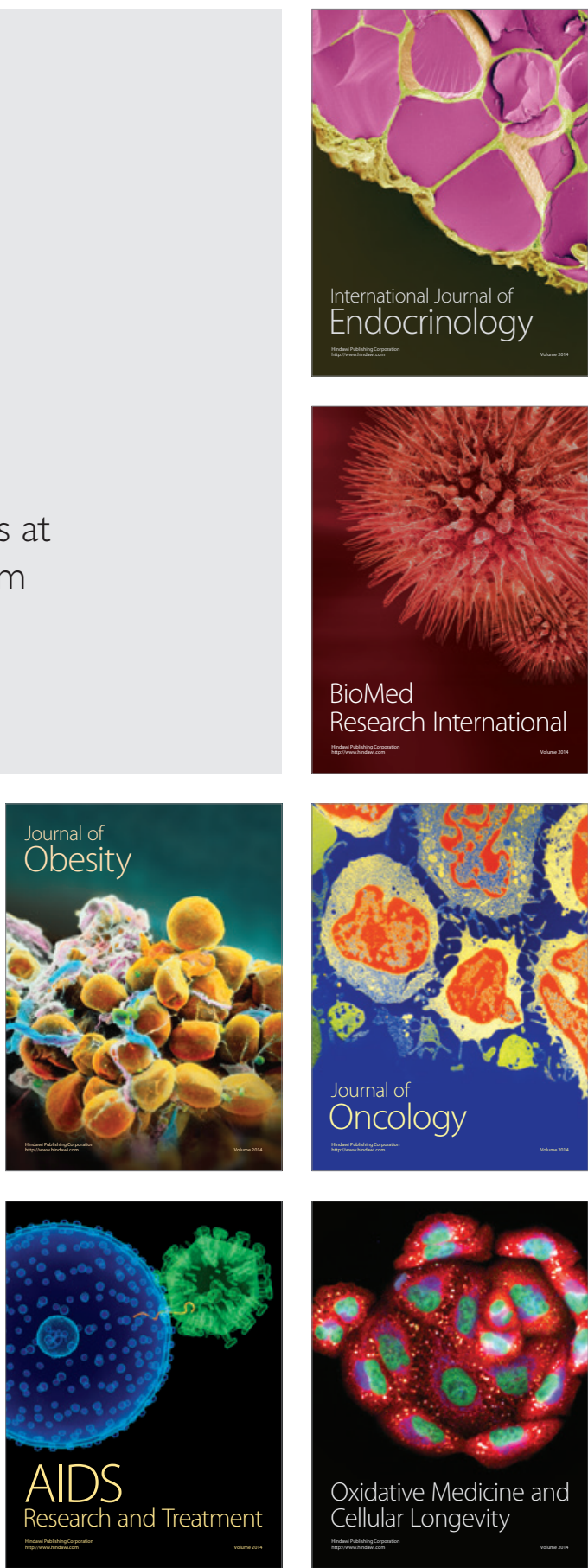